\title{
PortuGame: Ferramenta de Auxílio ao Ensino e Aprendizagem do Novo Acordo Ortográfico da Língua Portuguesa
}

\author{
Adriana Clericuzi ${ }^{1}$, Tarcísio Ferreira Grilo $\mathrm{Jr}^{2}$., Adriano Martins Pontes², Ana \\ Carolina Costa De Oliveira ${ }^{2}$, Jociquele Santana Soares ${ }^{1}$ and Wesllen Albuquerque \\ De Souza ${ }^{1}$
}

${ }^{1}$ Departamento de Ciências Exatas - Universidade Federal da Paraíba (UFPB), Rio Tinto, PB - Brasil

${ }^{2}$ PBSoft - Av. Expedicionários, 481, Expedicionários, João Pessoa, Brasil

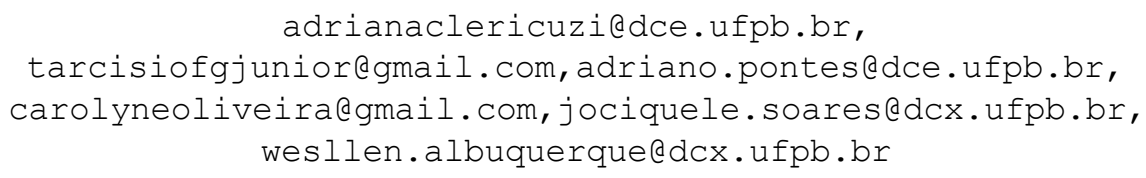

\begin{abstract}
This article aims to present the development process of the PortuGame application, which is a tool to aid the teaching and learning of orthographic changes implemented in the New Orthographic Agreement of the Portuguese Language. The methodological study was applied, where several activities are carried out to produce the application that will be applied throughout the text. As main results, there is an application that shows the user quickly what are the most relevant spelling changes and mainly offers a quiz to practice the new rules where users will learn while playing.
\end{abstract}

Resumo. Este artigo tem como objetivo apresentar o processo de desenvolvimento do aplicativo PortuGame, que é uma ferramenta de auxílio ao ensino e aprendizagem das mudanças implementadas pelo Novo Acordo Ortográfico da Língua Portuguesa. O estudo metodológico foi aplicado-prático, onde se desenvolveu várias atividades para produção do aplicativo que serão descritas ao longo do texto. Como principais resultados, tem-se um aplicativo que mostra ao usuário de forma rápida quais as mudanças ortográficas mais relevantes e principalmente disponibiliza um quiz. para prática das novas regras onde os usuários aprenderão jogando.

\section{Introdução}

Ser um educador hoje em dia significa usar toda a tecnologia disponível para tornar o aprendizado em sala de aula mais emocionante para seus alunos, inclusive, disponibilizando conteúdo on-line para acesso de todos, principalmente quando fala-se no ensino do idioma português, pois é uma língua que vive em constante mudança. As 
mais recentes dizem respeito ao Novo Acordo Ortográfico da Língua Portuguesa (NAOLP).

Para unificar as regras gramaticais foi criado o Novo Acordo Ortográfico da Língua Portuguesa que é um conjunto de regras a respeito da escrita que foi assinado em 1990 e estabeleceu atualizações ortográficas para a língua portuguesa, além da uniformidade da escrita dos países falantes do português. O português é uma língua neolatina falada oficialmente em nove países que formam a Comunidade dos Países de Língua Portuguesa (CPLP), são eles: Portugal, Brasil, Angola, Moçambique, Cabo Verde, Timor-Leste, São Tomé e Príncipe, Guiné-Bissau e Guiné Equatorial. Devido à complexidade do idioma o português de Portugal sofreu grandes variações regionais em cada um dos nove países espalhados pelo mundo.

No Brasil o NAOLP está em vigor desde 2009, mas seu uso passou a ser obrigatório em janeiro de 2016, essas alterações geram dificuldades de compreensão nos alunos que se confundem com as modificações impostas. Contudo, para Betin [2013] muitos alunos argumentam que os professores encontram mais dificuldades que os alunos em relação ao novo acordo ortográfico. Tudo isso ocorre por que depois que se aprende uma regra torna-se difícil desaprendê-la. As novas regras são criadas para se adequar a realidade da língua em constante transformação.

Para ajudar na fixação das mudanças do novo acordo ortográfico, tem-se utilizado a tecnologia da informação no ambiente escolar. Uso de computadores, smartphones, tablets e outros dispositivos, já é uma realidade para professores e alunos. Além do uso do computador para verificar a grafia correta das palavras provocadas pelas recentes modificações do Novo Acordo, os jogos educacionais vêm sendo utilizados como formas amigáveis de expor o conteúdo em sala de aula Pires, Navarro e Pires [2015].

Segundo Rela et al. [2006] a tecnologia não é a porta de entrada para o melhoramento da educação, nem lhe dará todos os respaldos para buscá-la, no entanto ela é um instrumento que abre portas para novos direcionamentos metodológicos e pedagógicos, que podem solucionar problemas de nostalgia, comunicação e informação. Isso originou o interesse entre os profissionais da área tecnológica e educacional pelo desenvolvimento de novas atividades e jogos educacionais para plataformas virtuais, em que a característica principal é a mobilidade do aluno, que pode estar distante fisicamente uns dos outros e também em espaços formais de educação através da internet.

Sendo assim, o presente trabalho tem como objetivo apresentar o processo de desenvolvimento do aplicativo educacional PortuGame que serve como ferramenta de auxílio para o processo de ensino e aprendizagem do novo acordo ortográfico.

\section{Electronic Learning}

O e-learning é uma modalidade de educação através da qual as aulas são mediadas pelo computador e de forma não presencial. Diferente do método de ensino tradicional, esse modelo proporciona o acesso aos conteúdos de forma online e a relação com o professor é de maneira remota. Na opinião de Ruhe e Zumbo [2009], há uma certa diferença entre a educação a distância e o e-learning, no aprendizado à distância o aluno escolhe a hora 
e o local de sua preferência, seja qual for, para estudar sem ter contato com o professor, em sua definição educação a distância é um termo genérico para designar a separação física entre os professores e os alunos.

Em contrapartida o e-learning seria um programa distribuído pela internet que possui interatividade no processo de aprendizagem e comunicação entre os alunos apesar da distância física entre eles. Basicamente, conclui se que a educação a distância seria um aprendizado individual e o e-learning um aprendizado compartilhado, ambos baseados no modelo de ensino não presencial, por exemplo os fóruns de discussões online e aplicativos compartilhados. Para Clark e Mayer [2011], o e-learning tem como foco as instruções, vindas de um dispositivo digital, que tem como finalidade apoiar a aprendizagem, ou seja, ele é transmitido por meio de textos, ilustrações, animações, vídeo falado, entre diversas outras aplicações online.

$\mathrm{Na}$ abordagem de Gomes [2016] o e-learning seria tecnologicamente a internet e serviços de publicação e de comunicação, e pedagogicamente a interação professor-aluno e aluno-aluno visando a colaboração entre eles. Em sua perspectiva a definição que melhor se encaixa seria "a utilização das novas tecnologias multimídia e da internet, para melhorar a qualidade da aprendizagem, facilitando o acesso a recursos e a serviços, bem como a intercâmbios e colaboração a distância" EUR-Lex [2002]. Pois essa definição, apesar de claramente mostrar um ambiente de formação a distância com base na comunicação e colaboração, permite outras leituras e a existência de "níveis" diferentes em termos de prática do e-learning. Neste sentido, o e-learning tem a função de integrar a aprendizagem através de ferramentas digitais a exemplo da utilização de jogos educacionais. De forma geral, os jogos educacionais nos permitem novas experiências, viver um mundo lúdico e dinâmico. Diferente do ambiente estático do quadro e giz que já não tem mais atração, pois se tornou monótono Santana et al. [2015]. Os smartphones abriram amplas e novas possibilidades de uso dos jogos digitais e permitiram a incorporação de milhões de jogadores de diferentes perfis etários e sociais Fleury, Nakano, Cordeiro, [2014].

Os aplicativos estão tirando a educação da sala de aula e colocando-a nos bolsos dos alunos. Atualmente grande parte dos jovens possuem dispositivos móveis e acessam seus aplicativos de qualquer lugar, a qualquer hora. Com isso em mente, devemos analisar a importância do uso de aplicativos na educação e considerar a adição de aplicativos à sua educação, esteja no ensino médio, na faculdade, na pós-graduação ou buscando educação continuada como um adulto.

Os aplicativos móveis podem ser utilizados de várias maneiras na educação, por exemplo, após uma aula, o professor pode disponibilizar, textos ou exercícios para os alunos lerem o conteúdo que foi ministrado quantas vezes quiserem. Outras possibilidades é o acesso a leitura de e-books, ouvir palestras gravadas ou concluir tarefas de casa on-line.

\section{Abordagem Metodológica}

Em relação aos procedimentos metodológicos para realização deste trabalho, primeiramente, realizou-se uma pesquisa bibliográfica, para obter o conhecimento necessário para desenvolver uma contextualização, argumentos e observações. De acordo com Rummel [1997] esta pesquisa é aplicada-prática por objetivar a aplicação 
dos tipos de pesquisa relacionados às necessidades imediatas dos diferentes campos da atividade humana. A partir daí, apresentaremos as etapas que constituíram o processo de desenvolvimento do aplicativo, assim como as decisões e as tecnologias utilizadas.

Destacar-se o público alvo de graduandos do Curso de Letras, professores e alunos que utilizam o tema para estudo. Uma vez definido o público foram realizadas várias reuniões multidisciplinares. Nela conversamos com uma professora de português para levantarmos as questões mais importantes que seriam inseridas no aplicativo (roteiro, interfaces e menus). Após esta fase foi discutida a elaboração de layouts para a professora de português aprovar. Depois da aprovação do layout pela cliente, passamos para parte de desenvolvimento e o levantamento de regras ortográficas (quiz) para serem inseridas no aplicativo.

Devido complexidade no desenvolvimento nativo, optou-se pelo desenvolvimento em frameworks multiplataformas, portanto utilizou-se o flutter para desenvolver o aplicativo numa única base de código e executá-lo nas diferentes plataformas. Para o desenvolvimento, teste e validação do PortuGame foi utilizado o flutter que tem capacidade de reload, que permite mudanças rápidas no código, com os resultados das mudanças visualizadas rapidamente aumentando a produtividade no desenvolvimento.

Assim que a primeira versão do aplicativo foi finalizada, o jogo foi apresentado para o cliente, que fez sua avaliação e sugestões de mudanças. Houve outras interações para os ajustes finais. Finalmente entregamos para a cliente definitivamente o jogo finalizado. Na próxima seção o aplicativo será apresentado.

Espera-se que o desenvolvimento deste app possa proporcionar uma maneira agradável e divertida do aprendizado da nova ortografia, de maneira que o usuário se sinta estimulado a continuar utilizando e consequentemente adquira conhecimento.

\section{Roteiro do PortuGame}

O processo de criação da tela inicial (Figura 1) foi o primeiro a ser realizado e teve início a partir dos elementos definidos no brainstorming e criados no roteiro feito com a professora de português. 


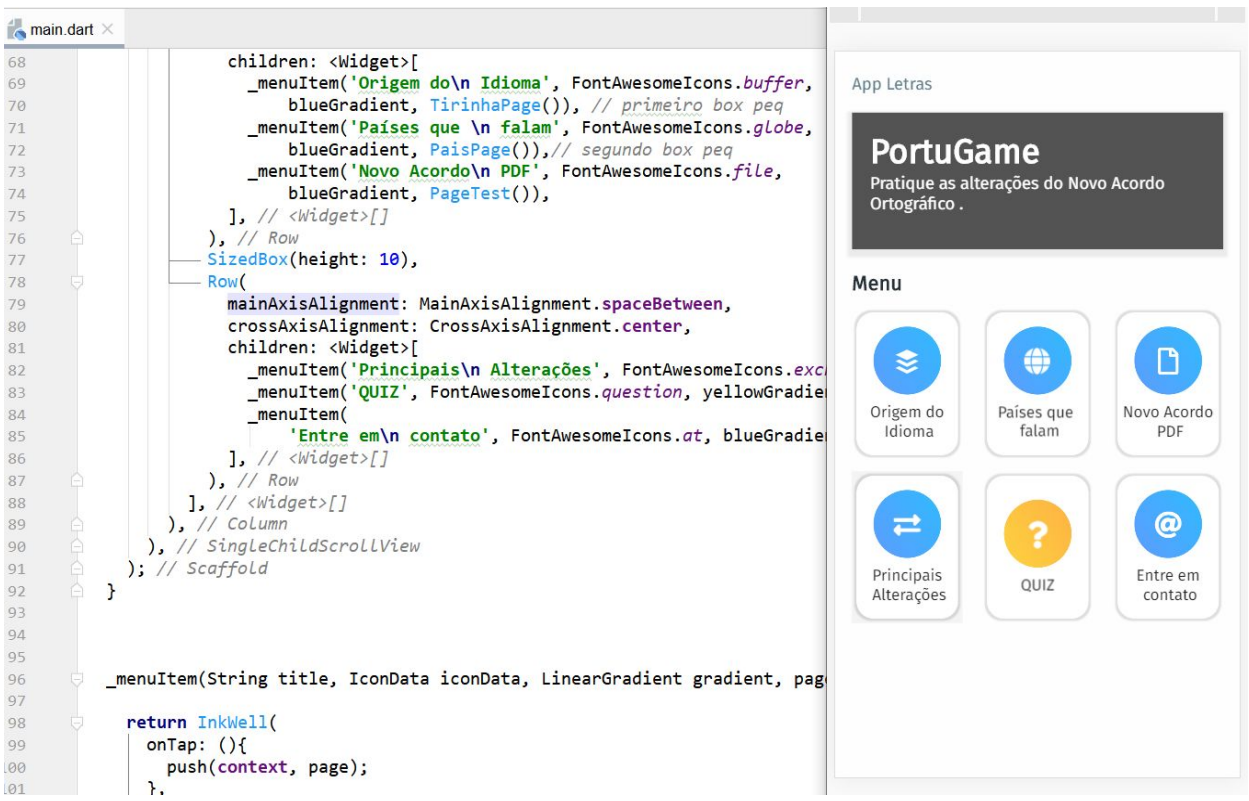

Figura 1: Tela inicial do PortuGame.

A linguagem utilizada para o roteiro é baseada na literatura juvenil evitando um ambiente complexo, pensando na aplicação prática. A interface inicial do app tem seis botões. A primeira fala sobre a origem da língua Portuguesa e as mudanças desse idioma até os dias atuais. A segunda mostra os nove países que falam oficialmente o português e suas variações. A terceira mostra o texto do Novo Acordo Ortográfico da Língua Portuguesa (completo em pdf). A quarta apresenta as alterações mais evidentes. A quinta parte é um jogo de perguntas e respostas (quiz) que contém questões a respeito das mudanças Novo Acordo Ortográfico da Língua Portuguesa e finalmente a última diz respeito ao contato para dúvidas.

\subsection{Menu: Origem do idioma}

No processo de criação desta interface (Figura 2) os primeiros elementos a serem desenvolvidos foram os dois personagens que iriam contar, de forma sucinta, a história da origem do idioma português. Para tal, os softwares CorelDraw, Photoshop e Illustrator foram empregados para criar as imagens entre outros recursos imagéticos que formam a interface gráfica. 


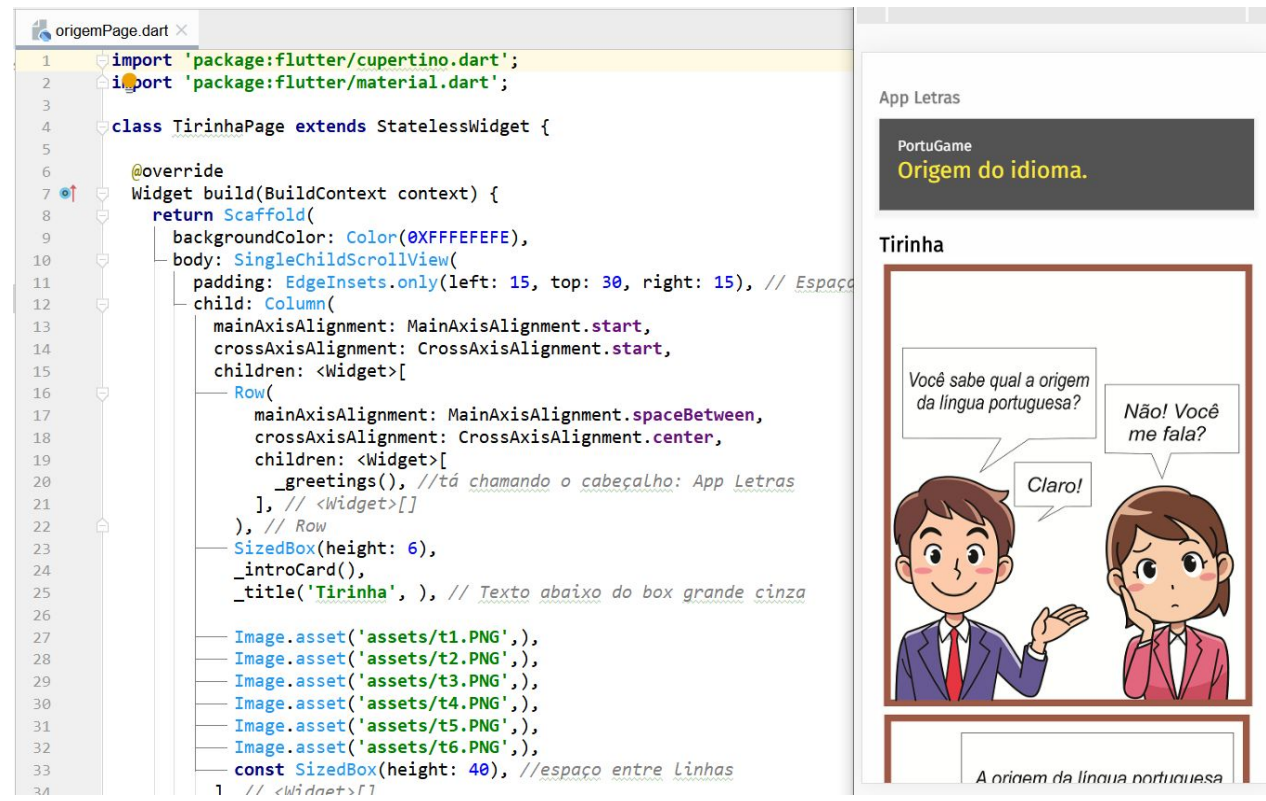

Figura 2: Origem do idioma

\subsection{Menu: Países que falam Português}

A Figura 3 refere-se a lista dos nove países que falam oficialmente o português e ainda contém curiosidades sobre esses locais.

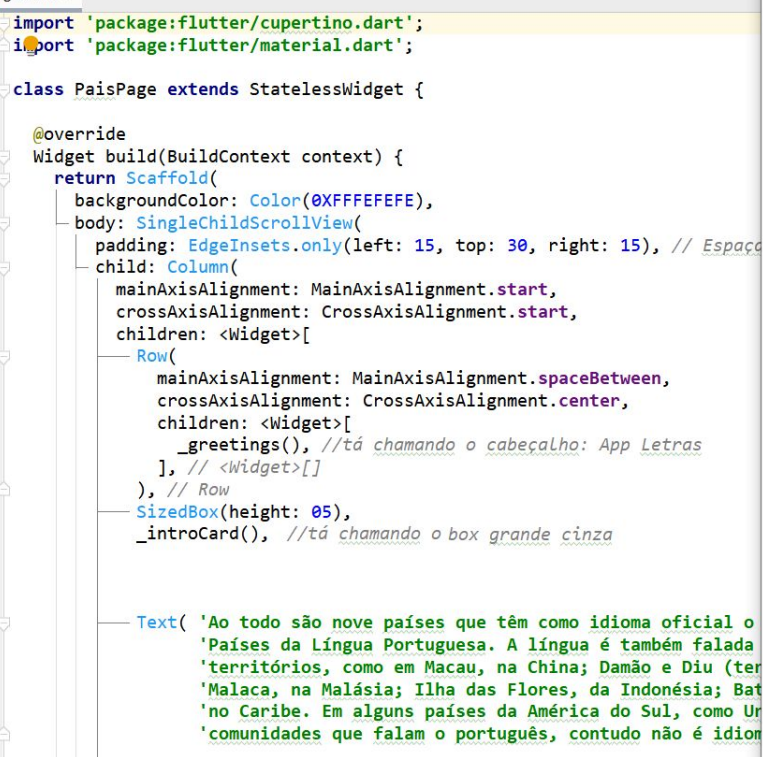

Ao todo são nove países que têm como idioma dospaíses da Língua Portuguesa. A língua é tambén falada por uma parte da população em outrosterritorios, como em Macau, na China; Damáo e Diu (territorio da Uniáo da india); Goa, na Indonésia; Batticaloa, no Sri Lanka; e nas Ithas ABC, no Caribe. Em alguns paises da America do Sul, como Uruguai, Venezuela, Paraguai e Guiana, hácomunidades que falam o português, contudo

1) ANGOLA:

A Angola é um país no continente africano. territorio angolano sofreu influência
dosportugueses desde o século XV, tendo sido uma de suas colônias. A independência de Portugaldeuse em há tambèm outras linguas pas possuemestatuto de lingua nacionat como quimbundo, segunda língua étnica mais falada. 2) BRASIL:

Figura 3: Países que falam Português 


\subsection{Menu: Quiz}

Nesta aba tem-se um jogo de perguntas e respostas (quiz) onde o usuário tem que responder corretamente questões que são colocadas de forma aleatória, sendo assim, a ordem que aparecerá na primeira vez, não é a mesma para outra vez. A tela que irá gerar a pergunta é uma página padrão que chama as perguntas e alternativas de um arquivo na nuvem (google sheets). Assim que o usuário clica a resposta é dada automaticamente. A princípio foram cadastradas 15 perguntas, mas podem ser cadastradas inúmeras perguntas pelo desenvolvedor da aplicação.

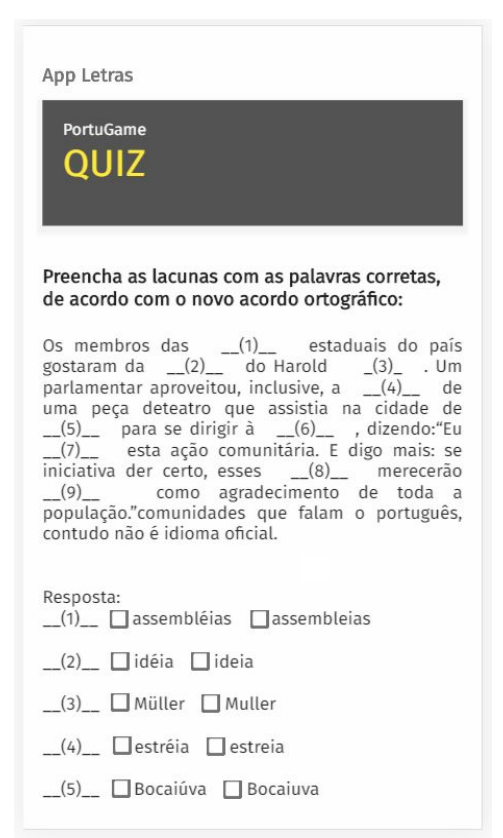

Figura 4: Quiz

Vale salientar que as perguntas devem ter um texto, mas as alternativas podem ser dispostas de forma variada com duas alternativas ou mais. A partir do clique e envio da resposta o usuário poderá ver se errou ou acertou e aproveitar o momento para revisar o conceito abordado pela pergunta através do feedback textual disponibilizado.

\subsection{Outros Menus}

Neste tópico será apresentado as telas referentes aos botões: Novo Acordo PDF, Principais Alterações e Entre em contato. Na primeira tem-se o link para arquivo em pdf (Figura 5a.) do texto completo publicado pelo senado federal do NAOLP, bem como todas as páginas do arquivo em pdf foram comprimidas como imagens sem haver danos à qualidade do texto que pode ser lido integralmente pelo usuário. No meio, tem-se página Principais Alterações (Figura 5b.), onde encontra-se as principais e mais relevantes dicas das alterações do NAOLP. 


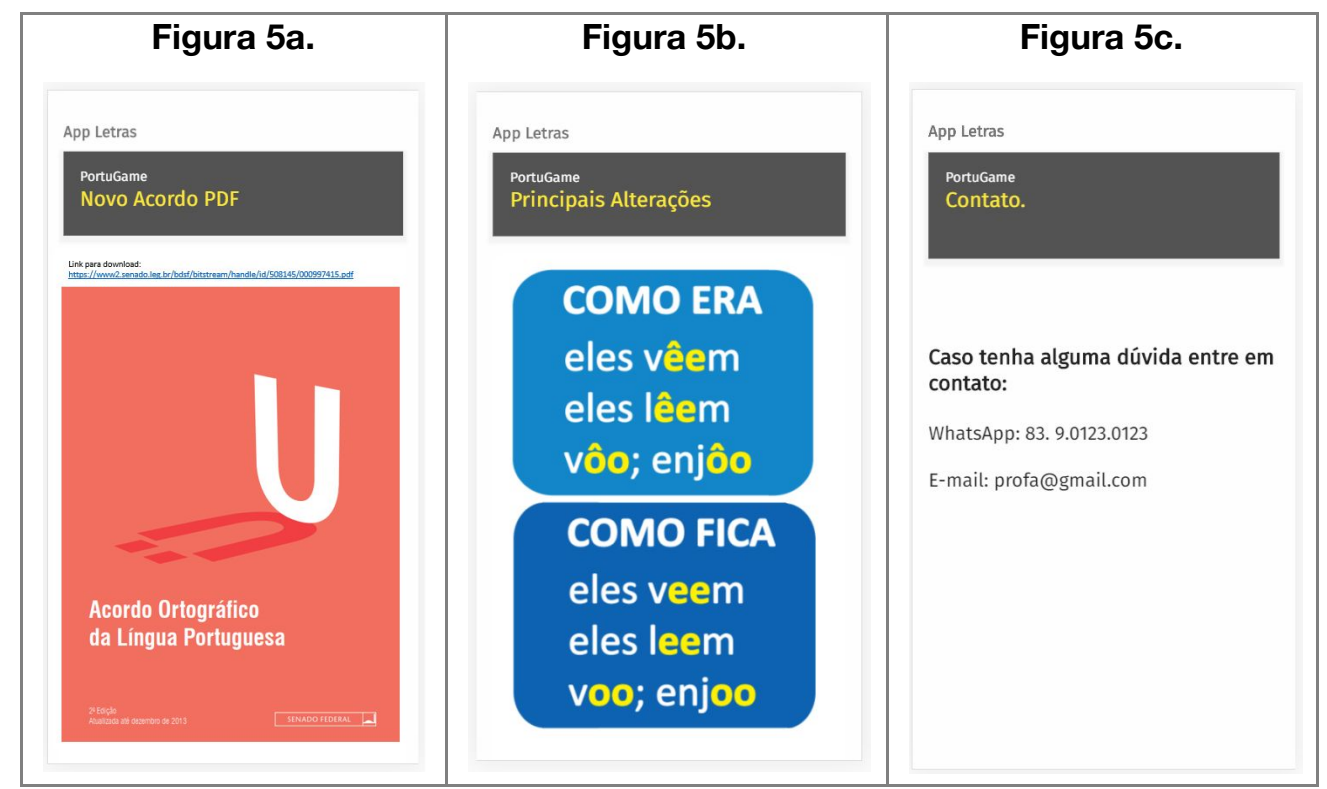

Figura 5: Outros

$\mathrm{Na}$ terceira parte da figura $5 \mathrm{c}$. tem-se a tela Entre em contato que apresenta os dados de contato da professora de português para o usuário entrar em contato caso haja alguma dúvida.

\section{Considerações Finais}

O propósito principal deste trabalho foi apresentar o processo de desenvolvimento do aplicativo PortuGame que é uma ferramenta focada no estudo do Novo Acordo Ortográfico da Língua Portuguesa. Este aplicativo é um repositório de textos e dicas voltados para o estudo as alterações impostas pelo NAOLP e também é capaz de praticar a nova ortografia através de um jogo educativo (quiz) proporcionando um ótimo entretenimento para o seu público-alvo.

Através de várias reuniões entre os membros da equipe, a ideia foi se tornando realidade, toda a equipe trabalhou home office pois o trabalho foi desenvolvido em época de isolamento social, por causa da Covid 19. A divisão do trabalho foi realizada pela líder da equipe que realizava as reuniões com a professora de português e depois se reunia com a equipe de desenvolvimento para repassar as tarefas e guiar todos para rumo do que se queria alcançar e sobre quais os pontos positivos e negativos surgiram ao decorrer dessa jornada, alimentando os positivos e tentando corrigir os negativos.

Todo o processo foi muito importante e desafiador, pois, todos os envolvidos tentaram dar o seu melhor nas mais diversas atribuições, haja vista que para se construir uma ferramenta dessas são levados em consideração os mais diversos conhecimentos nos temas em questão: nova ortografia, sistemas computacionais para construção do jogo (quiz), através de várias ferramentas e métodos. Essa divisão das atividades se deu pelo conhecimento individual de cada membro, explorando os mais diversos ramos de 
atuação. Essa junção fez surgir uma equipe bem dinâmica, com uma distribuição harmoniosa e que está trazendo uma ótima perspectiva de sucesso. O bom de tudo isso é que essas partes do app exploram a nova ortografia das mais diversas formas, onde os jogadores aprenderam jogando, e mais que isso, conquistarão conhecimentos que os tornarão melhores cidadãos, conscientes de seus direitos e deveres para toda a vida.

\section{Referências}

Betin, D. (2013) Professores sentem mais dificuldades com o Novo Acordo Ortográfico Digitais

PUC-Campinas,https://digitaispuccampinas.wordpress.com/2013/04/29/novo-acordo -ortografico-confunde-cabeca-de-professores-e-estudantes/. [accessed on Set 20].

Clark, R. C. and Mayer, R. E. (2011). e-learning and the Science of Instruction: Proven Guidelines for Consumers and Designers of Multimedia Learning. John Wiley \& Sons.

EUR-Lex - C: 2002:179: TOC - PT - EUR-Lex (2002). http://eur-lex.europa.eu/legal-content/PT/TXT/?uri=OJ:C:2002:179:TOC, [accessed on Jan 20].

Fleury, A., Nakano, D. N., \& Cordeiro, J. H. D. 'O. (2014). Mapeamento da indústria brasileira e global de jogos digitais. São Paulo: GEDIGames: NPGT.

Gomes, Maria João (2005). E-learning: Reflexões em Torno do Conceito. In Paulo Dias e Varela de Freitas (orgs), Actas da IV Conferência Internacional de Tecnologias de Informação e Comunicação na Educação - Challenges'05, Braga: Centro de Competência da Universidade do Minho, pp. 229-336.

Pires, C. E., Queiroz, A. R. M. De, Navarro, D. D., Marinho, L. B. and Pires, V. F. (2015). Um Jogo Didático para Detecção de Problemas de Qualidade de Dados em Bancos de Dados Relacionais. Revista Brasileira de Informática na Educação, v. 23, n. 3, p. 98.

Rela, E., Da Rocha, K. M., Goulart, M. B. and Carvalho, M. J. S. (2006). Tecnologias da Informação e Comunicação: Aprendizagem por Projetos Interdisciplinares.

Ruhe, V.; Zumbo, B. D. (2009) Avaliação de educação a distância e e-learning. Porto Alegre: Penso Editora Ltda.,. 334 p.

Rummel J. F. (1997). Introdução aos procedimentos de pesquisa em educação. 3rd ed. Porto Alegre: Globo.

Santana, M. G., Silva, L. F., Dantas, M. V., Santos, C. A. N., \&amp; Coelho, P. M. F. (2015, October). Jogos digitais: brincadeira ou auxílio pedagógico? In Anais do Congresso de Inovação Pedagógica em Arapiraca (Vol. 1, No. 1). 